\title{
PO09 - Parenting promotion: recommendation during infant crying or tantrums and a child's feeding time
}

\author{
Graça Aparício (Portugal) ${ }^{1}$; Mara Marçalino (Portugal) ${ }^{1}$ \\ ${ }^{1}$ Polytechnic Institute of Viseu
}

Theme: Parenting/parenthood.

Keywords: Feeding time, infant cry, parenting, tantrums.

Introduction: Parenting role involves some stress, especially in infant cry/tantrums and during feeding time, leading to pursuit of nurse's counseling.

Objective: To identify evidence-based recommendations and best practice for parents coping with crying/tantrums and in the child's feeding time.

Methods: Systematic review of articles published among 2009-2014 in the following databases: CINAHL, Cochrane, MEDLINE, using descriptors and Boolean operators. Two reviewers assessed the studies' methodological quality and included 7 studies, one A evidence level, two B, and four expert opinions.

Results: Culturally congruent counseling is recommended by the reference nurse, accompanying parents by phone call/home care visit, especially if they are inexperienced. Providers should know the areas of online discussion to become aware of regarding current parental concerns, and instruct on children's development and advise positive attention, routines, clear boundaries, concrete and fair.

Conclusion: Early promotion of fair and consistent parenting minimizes the day-to-day difficulties and the child's future behavior.

\section{PO10 - A safe school day for a diabetic child}

\author{
Svetlana Lorvi-Talisainen (Estonia) ${ }^{1}$; Annika Härmits (Estonia) ${ }^{1}$ \\ Sirje Multram (Estonia) ${ }^{1}$ \\ ${ }^{1}$ Foundation for School Health Care in Tallinn
}

Theme: School health.

Keywords: Diabetes, networking, school.

Background: In the last five years, the number of children under the age of 18 with type 1 diabetes in Estonia has increased by $5 \%$ annually. Every school has approximately one to three diabetic pupils. School staff lack knowledge of the management of the disease.

Objective: To ensure the safety of diabetic children at school.

Method: It is a school-based intervention programme which is based on training, capacity building, networking, assessment surveys, support groups in 140 schools of Estonia.

Results: Every pupil with type 1 diabetes has a support person. Members of the network have clearly defined roles. Schoolchildren know how to help their diabetic peers. The diabetic child is capable of assessing their own health status (blood glucose, carbohydrate 